\title{
Enterprise Networks for Competences Exchange: A Simulation Model
}

\author{
Marco Remondino, Marco Pironti, and Paola Pisano \\ e-Business L@B, University of Turin \\ 10145 Torino, Italy \\ \{remond,pironti,pisano\} di.unito.it
}

\begin{abstract}
A business process is a set of logically related tasks performed to achieve a defined business and related to improving organizational processes. Process innovation can happen at various levels: incrementally, redesign of existing processes, new processes. The knowledge behind process innovation can be shared, acquired, changed and increased by the enterprises inside a network. An enterprise can decide to exploit innovative processes it owns, thus potentially gaining competitive advantage, but risking, in turn, that other players could reach the same technological levels. Or it could decide to share it, in exchange for other competencies or money. These activities could be the basis for a network formation and/or impact the topology of an existing network. In this work an agent based model is introduced $\left(\mathrm{E}^{3}\right)$, aiming to explore how a process innovation can facilitate network formation, affect its topology, induce new players to enter the market and spread onto the network by being shared or developed by new players.
\end{abstract}

Keywords: Process Innovation, Enterprise Management, Network Topology, Business Process, Agent Based Simulation.

\section{Introduction}

Unlike product innovation, which is targeted towards product engineering, development and commercialization activities, process innovation relates to improving organizational processes. Our understandings of business process innovation come from the growing researches on organizational learning and knowledge management. The transfer and sharing of process innovation is not easy to attain, but information sharing/knowledge transfer (both within and across the boundary of the organization) is seen as an essential element for innovation. The network promote not only the transfer of knowledge (and the possible transfer of process) but also the creation of new knowledge as well, through synergies or competition. Within an organization, crossunit knowledge transfer can produce "creative abrasion" [3], generate "improvisational sparks" [4] and create new information patterns by rearranging information already in use and incorporating information previously neglected. Enterprises also actively look for external knowledge, for example by expanding their networks to learn new practices and technologies [5]. The process innovation could impact on the network not only by improving the knowledge of the involved enterprises, but also by 
changing the number of actors (exit and entry), and changing the numbers and patterns of link information [2]. The network can expand, churn, strengthen or shrink. At the level of a single enterprise, if it is the only one (or among the few) possessing an innovative process, it could become the focal point in a network, attracting others, wishing to link with it. Each network change is brought about by specific combination of changes in tie creation, tie deletion, and by changes in an actor's portfolio size (number of link) and portfolio range (numbers of partners) [2]. While [2] presents four types of network changes, they find that only an expanding network and a churning network are a reflection of a structural change, because new alliances are formed with new partners. An expanding network is brought about by an increase of new alliances without a deletion of old ones (meaning a large average of portfolio), together with an increasing portfolio range (more difference in partners). A churning network reflects the formation of new alliances and the deletion of existing alliances. While the average portfolio remains stable in term of the number of partners, there is a rotation of partners.

In order to empirically study how process innovation can affect an enterprise network, an agent based model is used. Agent based simulation is an effective paradigm for studying complex systems. It allows the creation of virtual societies, in which each agent can interact with others basing on certain rules. In this way, a social system can be observed as if it were a laboratory study, by repeating the experiments all the needed times, and changing just some parameters, by leaving all the others still (ceteris paribus analysis), something that would be impossible in the real system. The agents are basic entities, endowed with the capacity of performing certain actions, and with certain variables defining their state. In the model presented here, the agents are reactive, meaning that they simply react to the stimuli coming from the environment and from other agents, without cognitively elaborating their own strategies. An agent based model consists of a multitude of software agents (both homogeneous or heterogeneous), each type being endowed with particular local properties and rules, put together within an environment, formally described as a set of parameters and rules. When the model is formally built and implemented, emergent results can be observed, thus inferring cause-effect relations by simulating different core scenarios.

In the present work, social network theory is briefly analyzed and a definition of process innovation is given. Then, the comprehensive agent based model used is formally introduced, and it is discussed how it can be employed to study how a process innovation affects an enterprise network. Last, some empirical results coming from the model are given and the future work in this direction is discussed.

\section{Social Networks}

A social network is a social structure made of nodes (which are generally individuals or organizations) that are tied by one or more specific types of interdependency, such as values, visions, ideas, financial exchange, friendship. Social network analysis views social relationships in terms of nodes and ties. Nodes are the individual actors within the networks, and ties are the relationships between the actors. These concepts are often displayed in a social network diagram, where nodes are the points and ties are the lines. 
The idea of drawing a picture (called "sociogram") of who is connected to whom for a specific set of people is credited to [6], an early social psychologist who envisioned mapping the entire population of New York City. Cultural anthropologists independently invented the notion of social networks to provide a new way to think about social structure and the concepts of role and position, an approach that culminated in rigorous algebraic treatments of kinship systems. At the same time, in mathematics, the nascent field of graph theory [7] began to grow rapidly, providing the underpinnings for the analytical techniques of modern social network analysis. The strategic network perspective avers that the embeddedness of enterprises in networks of external relationships with other organizations holds significant implications for enterprise performance [10].

Specifically, since resources and capabilities such as access to diverse knowledge [11], pooled resources and cooperation, are often acquired through networks of interfirm ties, and since access to such resources and capabilities influences enterprise performance, it is important from a strategy perspective to examine the effect of network structure on enterprise performance [9]. Relationships between enterprises and their partners affect enterprises' alliance-building, behavior and performance. There is evidence that enterprises' network positions have an impact on their survival, innovativeness, market share [12], and financial returns [18]. However, evidence remains mixed on which particular patterns of inter-organizational relationships are advantageous for enterprises. One of the key ideas currently dominating the literature is [11]) open network perspective, according to which an enterprise can obtain important performance advantages when exploiting relationships to partners that do not maintain direct ties among one another. The absence of direct ties among a firm's partners (the presence of structural holes) indicates that these partners are located in different parts of an industry network, that they are connected to heterogeneous sources of information, and that their invitations to jointly exploit business prospects present the focal enterprise with access to diverse deal-making opportunities [1]. Several studies have shown that enterprises improve their performance as a result of maintaining relationships, whereas other studies have shown negative performance effects of firms' maintaining positions in open networks.

\section{Process Innovation}

A business process is a set of logically related tasks performed to achieve a defined business outcome [19], e.g.: sequencing of work routines, information flow and so on.

Process innovation is defined as "the introduction of a new method of production, that is, one yet tested by experience in the branch of manufacture concerned a new way of handling a commodity commercially" [16]. Edquist [20] defines process innovation like the result in a decrease in the cost of production. The drives of process innovation are primarily reduction in delivery lead time, lowering of operational costs, and increase in flexibility: process innovations are a firm's new way of design or manufacturing existing or new products. While newness on product innovation is defined at a macro level (market, industry), newness of process innovations is often defined at a micro level (enterprise and business unit). 
Meeus and Euist divide process innovations into two categories: technological and organizational innovations: technological process innovations change the way products are produced by introducing change in technology (physical equipment, techniques, system); organizational innovations are innovations in an organization's structure, strategy and administrative processes [16].

Process innovation can and should happen at various levels within the organization as no organization can depend solely upon innovation occurring at one level only. Successful organizations have an innovation process working its way through all levels of the organization.

\section{Impact on the Network}

Process innovation is a key factor for both competing in a market and creating links with other players. An enterprise owning a proprietary process would in fact exploit it, by gaining a competitive factor over those who do not possess it. On the other hand, it could decide to share it with other enterprises in exchange for money or, even better, in exchange for other competencies it does not know. This is the most important factor behind the creation of what we here define "network for competences exchange", i.e.: a social network of enterprises, where the ties semantically represent a synergy among players exchanging process innovations or, to a more general extent, competences.

Philippen and Riccaboni [13] in their work on "radical innovation and network evolution" focus on the importance of local link formation and the process of distant link formation. Regarding the formation of new linkages [8] finds that the process of new tie creation is heavily embedded in an actor's existing network. This means that new ties are often formed with prior partners or with partners of prior partners, indicating network growth to be a local process. Particularly when considering inter-firm alliances, new link formation is considered "risky business" and actors prefer alliances that are embedded in a dense clique were norms are more likely to be enforceable and opportunistic behavior to be punished ([10]; [2]). Distant link formation implies that new linkages are created with partners whom are not known to the existing partners of an actor. At the level of the enterprise, [11] shows that distant linkage that serve as bridge between dense local clique of enterprises, can provide access to new source of information and favorable strategic negotiation position, which improves the firms' position in the network and industry.

In order to examine and study how a process innovation can spread and affect the network for competences exchange, an agent based model is used. The model is a comprehensive one, showing the network dynamics for enterprises, and is described in detail in the next paragraph.

\section{The $E^{3}$ Agent Based Model}

The model has been developed at the e-Business L@B, University of Turin. It is built in pure Java, thus following the Object Oriented paradigm. This is particularly suitable for agent based modeling, since the individual agents can be seen as objects coming from a 
prototypal class, interacting among them basing on the internal rules (methods). While the reactive nature of the agents may seem a limitation, it's indeed a way to keep track of the aggregate behavior of a large number of entities acting in the same system at the same time. All the numerical parameters can be decided at the beginning of each simulation (e.g.: number of enterprises, and so on).

Everything in the model is seen as an agent; thus we have three kinds of agents: Environment, Enterprises and Emissaries $\left(\mathrm{E}^{3}\right)$. This is done since each of them, even the environment, is endowed with some actions to perform.

\subsection{Heat Metaphor}

In order to represent the advantage of an enterprise in owning different competences, the "heat" metaphor is introduced. In agent based models for Economics, the metaphor based approach [14] is an established way of representing real phenomena through computational and physical metaphors. In this case, a quantum of heat is assigned for each competence at each simulation turn. If the competence is internal (i.e.: developed by the enterprise) this value is higher. If the competence is external (i.e.: borrowed from another enterprise) this value is lower. This is realistic, since in the model we don't have any form of variable cost for competencies, and thus an internal competence is rewarded more. Heat is thus a metaphor not only for the profit that an enterprise can derive from owning many competences, but also for the managing and synergic part (e.g.: economy of scale).

Heat is also expendable in the process of creating new internal competences (internal exploration) and of looking for partner with whom to share them in exchange of external competences (external exploration). At each time-step, a part of the heat is scattered (this can be regarded as a set of costs for the enterprise). If the individual heat gets under a threshold, the enterprise ceases its activity and disappears from the environment. At an aggregate level, average environmental heat is a good and synthetic measure to monitor the state of the system.

\subsection{Environment}

The environment is regarded as a meta-agent, representing the world in which the proper agents act. It's considered an agent itself, since it can perform some actions on the others and on the heat. If features the following properties: a grid $(X, Y)$, i.e.: a lattice in the form of a matrix, containing cells; a dispersion value, i.e.: a real number used to calculate the dissipated heat at each step; the heat threshold under which an enterprise ceases; a value defining the infrastructure level and quality; a threshold over which new enterprises are introduced; a function polling the average heat (of the whole grid).

The environment affects the heat dispersion over the grid and, based on the parameter described above, allows new enterprises to join the world.

\subsection{Enterprise Agents}

This is the most important and central type of agent in the model. Its behavior is based on the reactive paradigm, i.e.: stimulus-reaction. The goal for these agents is that of surviving in the environment (i.e.: never go under the minimum allowed heat 
threshold). They are endowed with a heat level (energy) that will be consumed when performing actions. They feature a unique ID, a coordinate system (to track their position on the lattice), and a real number identifying the heat they own. The most important feature of the enterprise agent is a matrix identifying which competences (processes) it can dispose of. In the first row, each position of the vector identifies a specific competence, and is equal to 1 , if disposed of, or to 0 if lacking. A second row is used to identify internal competences or outsourced ones (in that case, the ID of the lender is memorized). A third row is used to store a value to identify the owned competences developed after a phase of internal exploration, to distinguish them from those possessed from the beginning. Besides, an enterprise can be "settled", or "not settled", meaning that it joined the world, but is still looking for the best position on the territory through its emissary. The enterprise features a wired original behavior: internally or externally explorative. This is the default behavior, the one with which an enterprise is born, but it can be changed under certain circumstances. This means that an enterprise can be naturally oriented to internal explorative strategy (preferring to develop new processes internally), but can act the opposite way, if it considers it can be more convenient. Of course, the externally explorative enterprises have a different bias from internally explorative ones, when deciding what strategy to actually take.

Finally, the enterprise keeps track of its collaborators (i.e.: the list of enterprise with whom it is exchanging competencies and making synergies) and has a parameters defining the minimum number of competencies it expects to find, in order to form a joint. The main goal for each enterprise is that of acquiring competences, both through internal (e.g.: research and development) and external exploration (e.g.: forming new links with other enterprises). The enterprises are rewarded with heat based on the number of competences they possess (different, parameterized weights for internal or external ones), that is spread in the surrounding territory, thus slowly evaporating, and is used for internal and external exploration tasks.

\subsection{Emissary Agents}

These are agents that strictly belong to the enterprises, and are to be seen as probes able to move on the territory and detect information about it. They are used in two different situation: 1) if the enterprise is not settled yet (just appeared on the territory) it's sent out to find the best place where to settle. 2) If the enterprise is already settled and chooses to explore externally, an emissary is sent out to find the best possible partners. In both cases, the emissary, that has a field of vision limited to the surrounding 8 cells, probes the territory for heat and moves following the hottest cells. When it finds an enterprise in a cell, it probes its competencies and compares them to those possessed by its chief enterprise verifying if these are a good complement (according to the parameter described in the previous section). In the first case, the enterprise is settled in a cell which is near the best enterprise found during the movement. In the second case, the enterprise asks the best found for collaboration). While moving, the emissary consumes a quantum of heat, that is directly dependant on the quality of infrastructures of the environment. 


\subsection{Main Iterations}

The main iterations for the simulation model are described in this section.

At step 0 , a lattice is created $(X, Y)$. A number $\mathrm{n}$ of enterprises are created, $k$ of them internally explorative and $n-k$ of them externally explorative. $\mathrm{X}, \mathrm{Y}, \mathrm{n}$, and $\mathrm{k}$ are set by the user, before the simulation starts.

At step 1, the environment checks if some enterprise reached the minimum heat threshold; if so, removes it from the world. After that, each enterprise, if idle (not doing anything) decides what behavior to follow.

At step 2, all the enterprises that selected to be EE move their emissary by one cell. All the IE ones work on the R\&D cycle (one step at a time).

At step 3, the EE enterprises check if the emissary finished its energy and, in that case, ask the best found enterprise for collaboration (they can receive a positive or negative reply, based on the needs of the other enterprise). The IE enterprises check if $\mathrm{R} \& \mathrm{D}$ process is finished and, in that case, get a competence in a random position (that can be already occupied by an owned competences, thus wasting the work done).

At step 4, the environment scatters the heat according to its parameters. Loop from step 1 .

\subsection{Parameters in the Model}

At the beginning of a simulation, the user can change the core parameters, in order to create a particular scenario to study. In figure 1, the section of the control panel containing the parameters is shown.

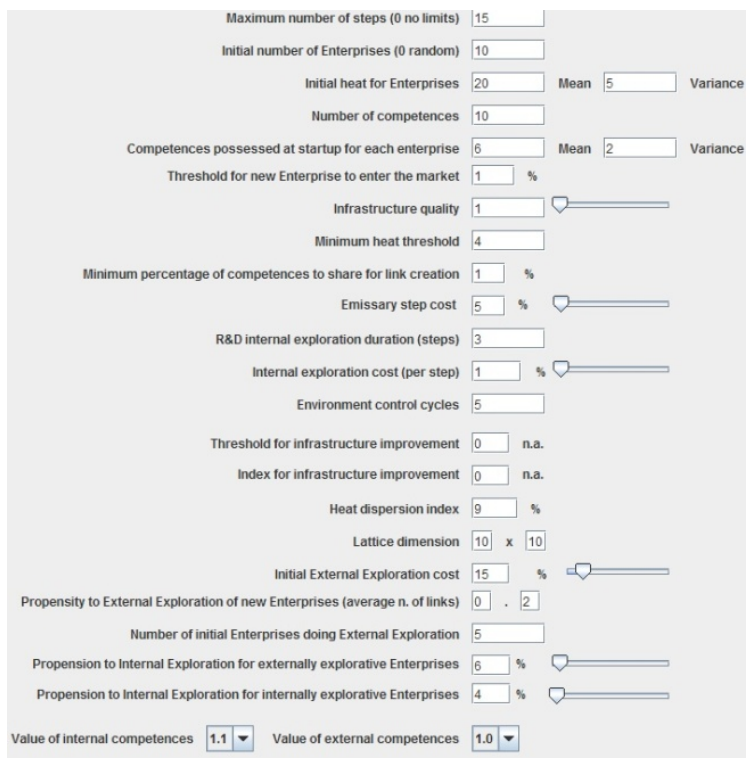

Fig. 1. The main control panel 
Some of the parameters are constituted by a scalar value, others are in percentage, others are used to define stochastic (normal) distributions, given their mean value and their variance. Here follows a synthetic explanation for the individual parameters:

Maximum number of steps: is the number of iterations in the model. 0 sets the unbounded mode.

Initial number of enterprises: is the number of enterprise agents present at start-up (0 is random).

Initial heat for enterprise: a normal distribution setting the initial energy for each enterprise, given the mean and the variance.

Number of competences: the length of the vector, equal for all the enterprises (metaphorically representing the complexity of the sector in which they operate).

Competences possessed at start-up: a normal distribution referring to how many processes an enterprise owns internally, given the mean and the variance.

Threshold for new enterprise to enter the market: a delta in the average heat of the world, after which a new enterprise is attracted in the market.

Infrastructure quality: affects the cost of external exploration.

Minimum heat threshold: level under which an enterprise cease.

Minimum percentage of competences to share for link creation: when asked for a competences exchange, the other enterprise looks at this value to decide whether to create a link or not.

Emissary step cost: percentage of the heat possessed by the enterprise spent for each step of its emissary, during external exploration task.

Internal exploration duration: quantity of steps for internally developing a new competence.

Internal exploration cost: percentage of the heat possessed by the enterprise spent for each step of internal exploration.

Environment control cycles: quantity of steps for sampling the average heat of the environment.

Heat dispersion index: percentage of heat evaporated at each step.

Lattice dimension: the dimension of the grid hosting the enterprise (i.e.: the whole environment).

Internal Exploration cost: "una tantum" cost for setting up an emissary for external exploration.

Propensity to External Exploration for new enterprises: when a new enterprise enters the market, it looks at the average number of links in the network. If more than this value, it behaves as externally explorative, otherwise internally explorative.

Number of initial enterprises doing external exploration: variable to divide the initial behavior. 
Value of internal/external competence: reward (heat) given for each internal/external competence possessed.

\section{Qualitative Results}

While the main object of this paper is to present the model itself as a tool for studying the effects of process innovation on enterprise networks, in the present paragraph some insights will be given about preliminary results obtained from the model itself. The presented ones will be mainly qualitative results, although the model can give many quantitative individual and aggregate results. In particular, a "computational only" mode is present in the model, allowing it to perform a multi-run batch execution. This is done according to the theory presented in [15]: the model is executed a defined number of times (chosen by the user) and the different outputs are sampled and collected at every $n$ steps (again, $\mathrm{n}$ decidable by the user) with the same parameters (in order to overcome sampling effects that could be caused by stochastic distributions) or by changing one parameter at a time by a discrete step, in order to carry on a ceteris paribus analysis on the model.

While this kind of analysis will be discussed in detail in future works, here some qualitative and semi-quantitative outputs will be discussed, obtained from the model. The model can give the following different kinds of outputs, when running in "normal" mode: 1) a real-time graph, depicting the social network, in which the nodes are the enterprises, whose color represent the behavior they are following at a given step, and the links are the ties indicating two or more enterprises mutually exchanging one or more competences. 2) A set of charts, showing in real time some core parameters, namely: average heat in the environment, number of links (in the network), number of links (average), number of enterprises doing internal exploration, number of ceased enterprises since the beginning, number of born enterprises since the beginning, number of available competences (overall), total number of skills possessed at the beginning, obtained by external exploration, obtained by internal exploration.

In figures 2, 3 and 4, the output graph is depicted at times 0 (no links), 100 and 500. These pictures belong to the same simulation, so the parameters are the same for all of them, with the only variation of time, giving a hint about the development of the

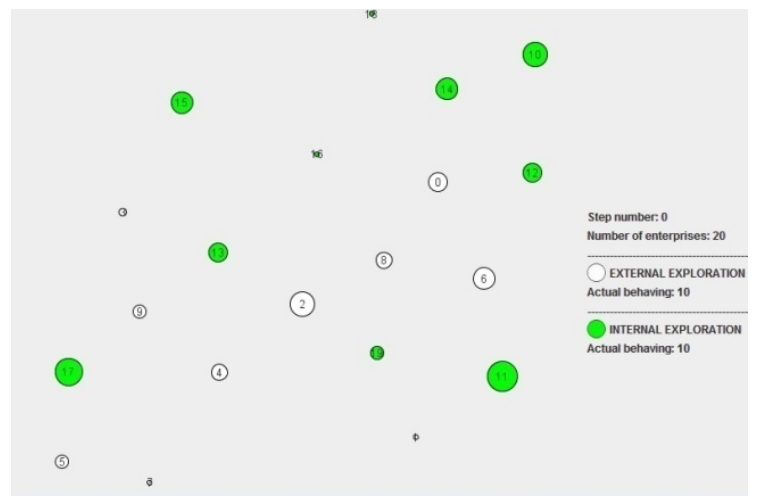

Fig. 2. The network at time 0 
enterprise network. In figure 2 the initial state of the network is shown, where no ties have been created, yet. A total of 20 enterprises is on the territory, 10 of which have an internally explorative behavior and the other 10 have an externally explorative mood. Internal competences are rewarded $10 \%$ more than external ones, but internal exploration strategy (e.g.: research $\&$ development) is $30 \%$ more expensive.

After 100 steps (figure 3) some new players have entered the market (an average of 1 new enterprise each 10 steps), meaning that the average heat of the system increased significantly; this can be thought as a starting network, attracting new players thanks to a good overall balance. Some ties have formed and many new competences (the dimension of enterprises) have been internally produced. After the initial steps in which $50 \%$ of the enterprise was doing internal exploration, now at the $100^{\text {th }}$ step, only one third (i.e.: $33 \%$ ) is doing that, since almost all the smaller players are trying to outsource them from the bigger ones, in order to gain some energy.

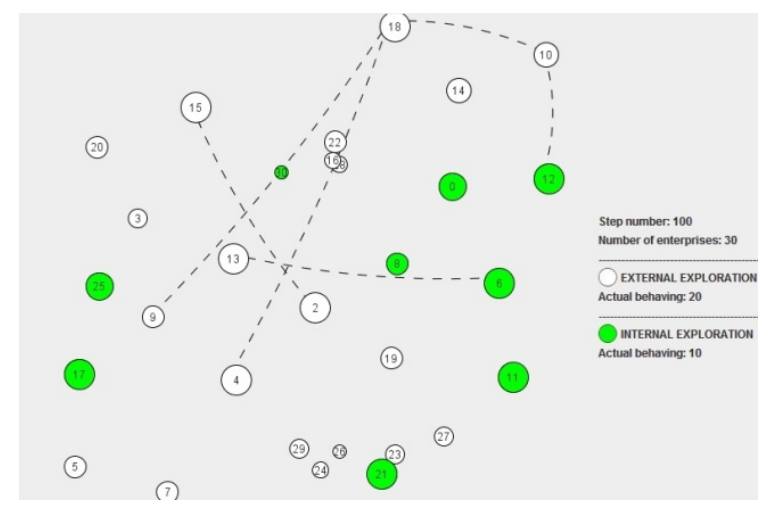

Fig. 3. The network at time 100

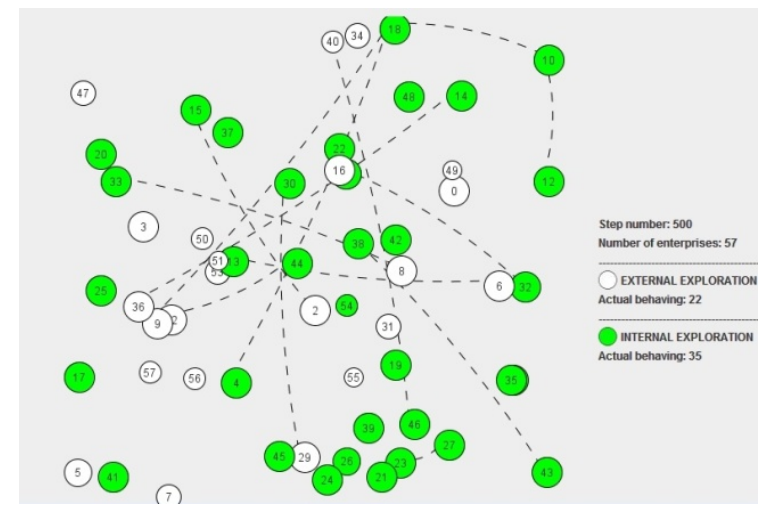

Fig. 4. The network at time 500 
Unfortunately, many of these small enterprises have no competence to give to the bigger one in exchange for theirs. They will eventually die (ceased enterprises) or try to change strategy, by starting an internal exploration. That's why at time 500 (figure 4) the total number of players increased again, but at a lower rate (1 every 15 steps, as an average) and now, in percentage, most of the survived enterprises are doing external exploration (62\% circa) and have become quite big (many internal competences possessed). Notice that in this experiment the threshold under which an enterprise must cease is a low value, meaning that few of them have to leave the market. This was done intentionally to show how enterprises can react and adapt their behavior even if they are modeled as reactive agents.

\subsection{Introduction of Process Innovation}

The impact of innovation diffusion on the network depends on the collaboration degree of the system. If the network is collaborative the diffusion of innovation strengthens the ties and increases the number of the links among organizations. The firms are more inclined to exchange competences than to create them inside the organization: they favor an externally explorative behavior that obviously strengthens the network. A feature referred to as "shock mode" is used in this section, allowing the user to stop the model at a given step, and change some inner parameter. For example, it is possible to add a specific competence to one enterprise only, so that it's the only one in all the network possessing it. In that way it becomes possible to study how and based on which dynamics this specific competence spreads on the network and which kind of competitive advantage it gives, in terms of central position in the network and bargaining power to obtain other competences not possessed internally.

In particular, here this is used to introduce a process innovation, in the form of a totally new competence; all the enterprises can achieve it, but only one of them possesses it at a starting point.

As shown in figure 5 and figure 6 , where some other output graphs obtained from the $\mathrm{E}^{3}$ simulation model are depicted, a collaborative network (A1) is defined by the existence of a large number of strong ties (compared to the number of enterprises). In our example, there are 10 strong ties among the enterprises. In a network structured in this way, the introduction and consequent diffusion of an innovation strengthens the collaborations through:

- An higher number of ties

- Ties that get even stronger (A2). In particular, the existing links get stronger and new ties are created ex novo.

In this case, the "shock effect" defined as the introduction of a process innovation brings effects in the networks that affect the decree of collaboration of the network itself. The introduction of an innovation in the network strengthens the links among the enterprises and the collaboration efficiency increases. 


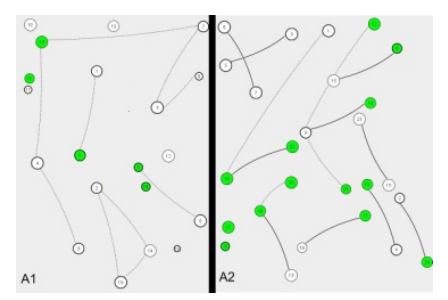

Fig. 5. Collaborative network before (A1) and after (A2) the introduction of an innovation

On the other side, in the case of a network with low propensity to collaboration the strong links do not exist or are a few when compared to the number of enterprises. The introduction of innovation in a network structured in this way can affect the degree of collaboration of the enterprises, according to industry complexity. In this situation (B1), it's possible to notice two different scenarios.

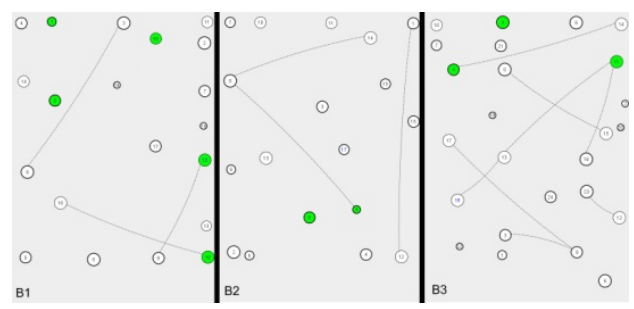

Fig. 6. Non-collaborative network before (B1) the introduction of an innovation. After (B2) in case of non complex industry, and after (B3) in case of complex industry.

If industry complexity is not too high (e.g.: the textile industry), as represented in B2, the number of ties is low and the firms prefer to create innovation inside the organization than receiving it from other organizations: in this case the firms favor internal exploration. So, when the complexity is low, the propensity to collaboration does not change and the enterprises are still loosely connected. The number of links could even increase, but much more slowly compared to the case of a collaborative network (B2 vs A2).

If industry complexity is high (B3), the diffusion of innovation increases the number of ties (but less than in a collaborative network) but the structure of ties is weak: in this case, again, the firms prefer an externally explorative behavior. So, in this case, the propensity to collaborate gets higher than before after the introduction of an innovation, but the links are always weaker when compared to the case of a collaborative network (B3 vs A2).

This qualitative analysis carried on through an agent based model allow to study "in the lab" a social system, like an enterprise network, and to study the effects of an innovation on collaborative and non-collaborative networks. While the purpose of this work is the description of the model itself, the qualitative results in this section show that the innovation diffusion in a network can create new ties among the enterprises (and thus it can be regarded as a driver for links creation in a network). Though, only 
in a collaborative network, or in a non-collaborative network acting in a complex industry, the number of the links increases significantly, while in non-collaborative networks acting in an industry which is not too complex, the number of links among the enterprises stays more or less the same, even after the introduction of the innovation (the enterprises being more focused on internal explorative behavior).

\subsection{An Empirical Evidence}

In order to propose an empirical validation of the obtained results two real world scenarios have been considered: Silicon Valley and Route 128. While the former succeeded in adapting to the transformations of the environment, the latter seems to be losing its competitive strength. Despite the similar origins, these regions developed different industrial systems: their different response to the crises happened during the 80 s made clear the differences of productive organization whose significance had been underestimated during the quick economic growth of the first decade. During the 70s both Silicon Valley, in Northern California, and Route 128, near Boston, were highly praised by the World for being the leading edges in technological advances in Electronics. Both were honored for their technical vitality, entrepreneurship, and incredible economic growth. The two realities had a similar beginning: university research and post-war financing.

At the beginning of the $80 \mathrm{~s}$, the enchant rapidly vanished; the chip producers, located in the Silicon Valley, lost their market to the Japanese competitors, while the producers of mini-computers, located in the Route 128 area, saw the passage of their customers to workstations and personal computers. Notwithstanding the two economies took very different roads; in the Silicon Valley a new generation of enterprises rose, producing semi-conductors and computers, joining the big players already settled. The success of realities like Sun Microsystems, Conner Peripherals and Cypress Semiconductor, along with the dynamism of companies like Intel and HewlettPackard proved that Silicon Valley had recovered its previous vitality. On the contrary, Route 128 showed few signs of recovery and, by the end of the decade, most of the producers located there had given away their crown to those settled in Silicon Valley, that became the headquarter of more than one third of the technology societies created after 1965. The market value of these companies increased of 25 billions, when compared to 1 billion of those located in the Route 128 area.

Silicon Valley region features has an industrial system which promotes collective learning and flexible adjustment among the producers specialized in a series of connected activities (collaborative network). The dense social network of this region, along with the open labor market, encourage research and entrepreneurship; the companies compete among them, but at the same time learn from each other and exchange competences to face the market.

On the contrary, the enterprises in the Route 128 region are fewer and independent among them (non-collaborative network), whose industrial system is mainly based on internal competences, not shared with others.

The two scenarios look alike those exemplified in the previous paragraph; while Silicon Valley resembles the example shown in A1-A2, Route 128 is similar to the one seen in B1-B3. Even if in a simplistic way, this real world case constitutes an 
empirical evidence supporting the qualitative results coming from the $\mathrm{E}^{3}$ model, and clarifies what kind of analyses can be carried on through this simulation tool.

\section{Conclusion and Outlook}

Process innovation is characterized by two important aspects: one critical and typical aspect is the ability to gather, develop and transform information and knowledge in a potential competitive advantage. The second aspect regards spending resources like time and money: the development of process innovation is usually time and resource consuming and is difficult to attain, especially when referring to radical cases. Though, process innovation is a key factor for building a network for competences exchange and a very important variable when considering the strategies performed by an enterprise; once possessed, the advantage can be exploited or shared. In the first case, the enterprise can gain customers and money, by being the only one (or among the few ones) possessing it. But it risks to lose its advantage as soon as other players can develop it. Another strategy is that of sharing the process innovation, in exchange for other competencies and/or money.

An agent based model is introduced in this work, aiming at capturing the dynamics behind the creation and the following modifications of an enterprise network for competences exchange, i.e.: a network in which enterprises can internally develop and/or share processes with other players. This is, by the way, one of the focal points behind the creation of industrial districts, enterprise clusters and so on. A well established network of this kind can attract new players, that will probably bring new knowledge and competences in it.

The model is formally discussed in detail, and so the agents composing it and its iterations. While studying quantitative results is beyond the purpose of this work, a qualitative analysis is described, and the network graph, one of the graphical outputs supplied by the model, is analyzed: in order to show how network dynamics emerge from the model and its parameters, settable by the user.

At the beginning, when the enterprises have few competences and high perception of how can be difficult develop and innovation process, they try to link with the enterprises that have already developed innovative processes. That's why, in an initial phase, the number of enterprises doing external exploration tends to increase. After some steps, the number of enterprises choosing external exploration is lower and lower and limited to the smallest players, or the newly arrived ones. The reason is that at the beginning, the enterprise's capability are low and the perception of the effort for developing a process innovation is high. The enterprise at this phase typically try to share and exchange competences with others that have already developed the innovative process, not having to face the risk of inside developing, even if this can be more gainful in the long run. As time passes by, the enterprises start to become bigger and be more conscious about their capabilities and knowledge, thus reducing the perception of the effort to develop innovative processes internally.

Another qualitative example is given, to show the difference among collaborative and non-collaborative networks, depicted by means of simulation, at the introduction of a process innovation; while in the former process innovation proves to be a driver 
for new link creation, in the latter the impact is quite smaller and almost irrelevant, especially if the sector is not a complex one.

To empirically validate these qualitative results, and in order to connect them to the real world, two cases are quickly analyzed, resembling those depicted in the computational examples: Silicon Valley and Route 128.

The model is comprehensive and its scope is wide. In future works other features will be described in detail, and also quantitative analysis will be carried on in order to study real-world cases (e.g.: existing industrial districts and so on) and the underlying dynamics that lead to their creations. In particular, computational only mode will be used to study the iterative behavior of networks, in ceteris paribus conditions (i.e.: by changing a single parameter at a time).

\section{References}

1. Zaheer, A., Bell, G.G.: Benefiting from network position: firm capabilities, structural holes, and performance. Strategic Management Journal (2005)

2. Koka, B.R., Prescott, J.E.: Designing alliance networks: the influence of network position, environmental change, and strategy on firm performance. Strategic Management Journal (2008)

3. Leonard-Barton, D.: Wellsprings of knowledge. Harvard Business School Press, Boston (1995)

4. Brown, J.S., Duguid, P.: Organizational Learning and Communities of Practice: Toward a Unified View of Working, Learning and Innovation. Organization Science 2, 40-57 (1991)

5. Kogut, B.: Joint ventures: theorical and empirical perspectives. Strategic Management Journal (1988)

6. Moreno, J.L., with foreword by White, W.A.: Who shall survive? A new approach to the problem of human interrelations. Nervous and Mental Disease Publishing Co. Psych. Abs., Washington, DC, 8, 5153; (Revised edition published by Beacon House in, Psych. Abs., 28, 4178) (1953)

7. Harary, F.: Mathematical aspect of electrical network analysis (1969)

8. Gulati, R., Gargiulo, M.: Where do interorganizational networks come from? American Journal of Sociology 104(5), 1439-1493 (1999)

9. Gulati, R., Nohria, N., Zaheer, A.: Strategic networks. Strategic Management Journal 21(3), 203-215 (2000)

10. Gulati, R.: Alliances and networks. Strategic Management Journal, Special Issue 19(4), 293-317 (1998)

11. Burt, R.S.: Structural Holes. Harvard University Press, Cambridge (1982)

12. Nohria, N.: The Differentiated Network: Organizing Multinational Corporations for Value Creation (1997)

13. Phlippen, S., Riccaboni, M.: Radical Innovation and Network Evolution (2007)

14. Remondino, M.: Agent Based Process Simulation and Metaphors Based Approach for Enterprise and Social Modeling. In: ABS 4 Proceedings, SCS Europ. Publish. House, pp. 93 97 (2003) ISBN 3-936-150-25-7

15. Remondino, M., Correndo, G.: MABS Validation Through Repeated Execution and Data Mining Analisys. International Journal of SIMULATION: Systems, Science \& Technology (IJS3T) 7 (September 2006) ISSN: 1473-8031

16. Sherer, Innovation and Growth: Schumpeterian Perspectives (2007) 
17. Srivardhana, T., Pawlowskiv, S.D.: ERP systems as an enabler of sustained business process innovation: A knowledge-based view. Science Direct (2007)

18. Rowley, T., Behrens, D., Krackhardt, D.: Redundant goverance structures: An analysis of structural and relational embeddedness in the steel and semiconductor industries. Strategic Management Journal 21, 369-386 (2000)

19. Davenport, T.H., Short, J.E.: The New Industrial Engineering: Information Technology and Business Process Redesign. Sloan Management Review, 11-27 (Summer 1990)

20. Edquist, C.: The Systems of Innovation Approach and Innovation Policy: An account of the state of the art. Paper presented at DRUID Conference, Aalborg, June 12-15 (2001) 